\title{
Effect of Water Stress in Soil Nitrogen Dynamics under Intercropping System with Maize and Sorghum
}

\author{
Asim Sharif ${ }^{1}$ and Utsab Thapa ${ }^{2}$
}

\section{Abstract}

Global warming, one of the most persistent threats to nature, is expected to result in severe droughts in many parts of the world. Droughts are supposed to effect individual plants and/or plant communities by changing their al biotic interactions. The objective of this study was to elucidate drought effects on soil nitrogen allocation in different aggregate sizes. This was done by growing Zea mays and Sorghum bicolor in monoculture and mixture. Nitrogen allocation under drought stress was traced using nitrogen stable isotope ${ }^{15} \mathrm{~N}$. Drought disintegrated soil aggregates into finer aggregates for sorghum monoculture and decreased the aggregate proportion in small macro-aggregate fraction for maize monoculture. For plant mixture, drought increased total nitrogen content in micro-aggregate fraction and uptake of added ${ }^{15} \mathrm{~N}$ in bulk soil. Hence, the study showed that mix planting maize and sorghum offer better resistance against changes in plant biomass and nitrogen content which suggests its effectiveness in nitrogen conservation during water stress. Moreover, intergrowing maize and sorghum under agroforestry systems also produce advantageous results.

Key Words: drought stress, intercropping, aggregate fractions, ${ }^{15} \mathrm{~N}$, plant biomass.

Sharif A., Thapa U. (2018): Effect of Water Stress in Soil Nitrogen Dynamics under Intercropping System with Maize and Sorghum. Forestry: Journal of Institute of Forestry, Nepal. No. 15: page 1 to 12.

\footnotetext{
${ }^{1}$ University of New Zealand, Author corresponding email address: asimsharif89@yahoo.com ${ }^{2}$ Government of Nepal, Ministry of Forests and Environment
} 


\section{Introduction}

Global warming refers to apparent increase in average global temperature resulting from the release of greenhouse gases (McCright, Dunlap 2000). Since 1990, the average global temperature has increased by $8^{\circ} \mathrm{C}$ (Hansen et al. 2006) and with the current rate of warming; the climate is expected to change, causing a rise in the sea level, increase in droughts and/or floods and change in species behavior (CarlssonKanyama 1998).

Vegetation is directly affected by climate as most species are sensitive to change in temperature and precipitation (Jacoby et al. 1996). Climate change is expected to create water shortage and extreme weather events causing low yields and loss of suitable areas for traditional crops (Olesen, Bindi 2002).

Soil water is an essential component for nutrient uptake and translocation as it induces nutrient flow and removes saline and/or toxic ions from the soil (Somma et al. 1998). Moisture stress restricts nutrient uptake (Farooq et al. 2009), reduces transpiration flow and effects nutrient acquisition by roots and their subsequent transport to the shoots (Garg 2003). Most studies on root-microorganism competition have been conducted using ${ }^{15} \mathrm{~N}$-labelling approach which allows study of short term competition for nitrogen uptake between microbial biomass and plants (Kuzyakov, Xingliang 2013).

Intercropping includes inter-specific competition and facilitation where one crop improves nutrient uptake in the other (Zhang, Li 2003), ensures better use of environmental resources, yield stability, biodiversity promotion, better performance under stress conditions and yield compensation in case one of the crops fails or underperforms (Willey et al. 1980). Both maize and sorghum are characterized by their high water use efficiency (Muchow 1989) and their intercropping is healthier and more resistant against pest colonization as compared to their monocultures (Amoako-Atta et al. 1983). Moreover, both species have been found to be very useful in agroforestry practices. Intercropping maize with leguminous fodder tree species exhibited a higher number of maize grains per year (Oliveira et al. 2016). Similarly, intercropping sorghum with Azadirachta indica and Albizzia lebbeck considerably increased the mean grain yield of sorghum due to mulching effect of the tree leaves (Tilander 1993). 
However, effect of drought on soil aggregate fractionation and allocation of nitrogen in different soil aggregates has not been studied in detail. Therefore, current study focuses on the responses of these crops to drought when they are grown individually and in intercropping.

To study the effect of drought stress in nitrogen uptake and allocation in different plant communities and its incorporation into different soil aggregate fractions, two grasses (Zea mays and Sorghum bicolor) were grown individually and in mixture for 60 days under controlled laboratory conditions.

\section{Materials and Methods}

\section{Site description}

Soil samples were taken from the top $25 \mathrm{~cm}$ of a Haplic Luvisol at a terrace plain of river Leine, located in the north-west of Göttingen, Germany. The mean annual temperature is $8.7^{\circ} \mathrm{C}$ and annual precipitation around $645 \mathrm{~mm}$. The soil is slightly acidic $(\mathrm{pH} 6.0 \pm 0.1)$ with $1.3 \mathrm{~g} / \mathrm{kg}$ total nitrogen $(\mathrm{N}), 12.6 \mathrm{~g} / \mathrm{kg}$ total carbon $(\mathrm{C})$, $1.4 \mathrm{~g} / \mathrm{cm}^{3}$ bulk density and a $\mathrm{C} / \mathrm{N}$ ratio of 9.8 . The soil consisted of $7 \%$ sand, $6 \%$ clay and $87 \%$ silt. The soil after sampling was air dried, mixed and passed through a 5-mm sieve.

\section{Experimental design}

A two-factorial experiment was set up in order to know how different plants interact with each other for nitrogen uptake under optimum and drought stress conditions. Two $\mathrm{C}_{4}$ plants maize (Zea mays) and sorghum (Sorghum bicolor) were used. Pregerminated seedlings of each species were planted in microcosms, each filled with $3 \mathrm{~kg}$ of soil. Two treatments were maintained in monocultures (4 plants of same species in each microcosm) and mixture (two maize and two sorghum plants in each microcosm). Unplanted control at a temperature of $20^{\circ} \mathrm{C}$, day-length of 14 hours and light intensity of $400 \mu \mathrm{molm}^{-2} \mathrm{~s}^{-1}$ was also maintained for the whole growth period. For the first 30 days of plant growth, optimum water level (70\% of field capacity) was maintained for all microcosms. However, after one month, half of the vegetated microcosms and 3 microcosms with unplanted soil were adjusted to optimum water level ( $70 \%$ of field capacity) while remaining half were kept at drought conditions (30\% of field capacity) for 30 days. Ten days before harvesting, ${ }^{15} \mathrm{~N}$ labeled potassium nitrate $(0.4 \mathrm{M})$ solution was prepared and added 
to 24 microcosms to provide nitrogen to plants. After harvesting, microcosms were emptied and shoots, roots were separated manually from the soil.

\section{Soil aggregate size fractionation}

Soil samples were dried to optimal moisture allowing limited mechanical stress to induce maximum brittle failure along natural planes of weakness. When individual soil clods reached desired condition, they were gently manually crumbled, all visible roots and stones removed, sieved using automatic sieving system at sieving speed of $70 \mathrm{rpm}$ for 1 minute and then separated into three aggregate size classes: $<0.25 \mathrm{~mm}$ (micro-aggregate), $0.25-2 \mathrm{~mm}$ (small macro-aggregate) and $>2 \mathrm{~mm}$ (macro-aggregate). The soil fractions were oven dried at $60^{\circ} \mathrm{C}$ and total nitrogen and proportion of ${ }^{15} \mathrm{~N}$ recovered were determined in different soil aggregates.

\section{Calculation \& statistical analysis}

To analyze the effect of drought and plant combination on nitrogen allocation and uptake in different pools, two-way ANOVA with Tukey HSD Test was applied. The effects were accepted statistically significant at $\mathrm{p}<0.05$. All analyses were conducted using Statistics 8.1 software.

\section{Results and Discussion}

\section{Soil aggregate size fractionation}

The results showed that soil fractions were dominated in the small macro-aggregate class $(0.25-2 \mathrm{~mm})$ for both water treatments irrespective of soils being planted or unplanted. For unplanted soils (Fig. 1a), micro-aggregate and macro-aggregate fractions were not affected by drought but there was a very significant increase in the proportion of soil fragments in small macro-aggregate fraction from 34.4 $\pm 4.4 \%$ to $47.5 \pm 0.3 \%$. In case of soils planted under maize monoculture, microaggregate and macro-aggregate fractions were unaffected but a significant decrease in small macro-aggregate proportion $(55.3 \pm 0.8 \%$ to $49.2 \pm 0.5 \%)$ was observed (Fig. 1b). For sorghum monoculture (Fig. 1c), a significant increment in microaggregate fraction $(15.8 \pm 3.7 \%$ to $29.7 \pm 0.5 \%)$ and for small macro-aggregate fraction $(50.5 \pm 0.6 \%$ to $57.5 \pm 0.2 \%)$ were observed but for macro-aggregate fraction, a strong decrease $(37.4 \pm 0.6 \%$ to $13.5 \pm 1.3 \%)$ was observed. A different effect was seen in plant mixture (Fig. 1d) where small macro-aggregate fraction was unaffected by drought. There was a significant increase in the proportion of soil

$$
-|4|-
$$


aggregates in micro-aggregate fraction from $16.7 \pm 0.1 \%$ to $28.8 \pm 0.1 \%$ while for macro-aggregate fraction; a significant decrease from $27.5 \pm 1.7 \%$ to $14.2 \pm 0.4 \%$ was observed.
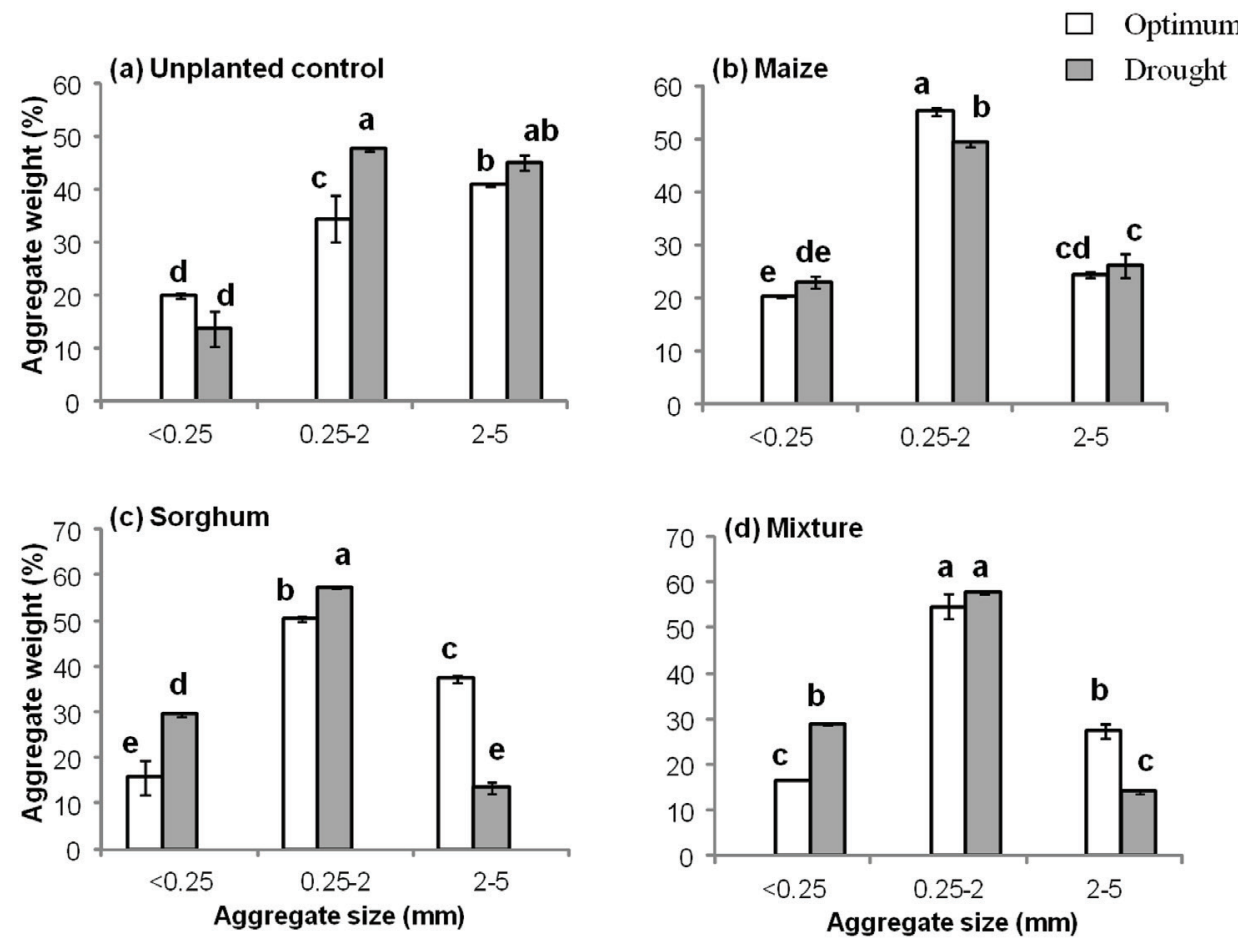

Fig. 1: Effect of drought in soil aggregate size fractionation under (a) unplanted condition, (b) maize monoculture, (c) sorghum monoculture and (d) mix planting of maize and sorghum. All values represent mean $\pm \mathrm{SD}(\mathrm{n}=3)$.

Change in moisture levels affect microbial and biotic activities which alter the decomposition rate and thus reorient soil particles (Singer et al. 1992). Soil aggregate fractionation process initiates from utilization of fresh soil residues which function as nucleation sites for fungal and microbial growth and results in binding of residue and soil particles into bigger aggregates (Puget et al. 1995). Micro-aggregates are formed inside the macro-aggregates that are composed of more recalcitrant soil carbon pool (Plante, McGill 2002). Further the significant increment in microaggregate fraction in sorghum monoculture and in plant mixture corresponded with the significant reduction in macro-aggregate fraction for the same crop combination. This has been attributed to reduction in exudates supply induced by 
drought stress which in turn destabilized macro-aggregates and dissociated them into finer aggregates (Jastrow 1998). Moisture availability enhances decomposition of organic matter and release of microbial exudates which can bind soil particles into bigger aggregates and stabilize the coarser aggregates (Jastrow 1998). This has also been associated to the effect of an enzyme glomalin that assists in retaining soil moisture during water stressed condition and thus promotes soil aggregation (Rillig et al. 1999). Further, release of root exudates gets suppressed under moisture stress condition (Jastrow 1998) which prevents binding of soil aggregates into aggregate fractions. Similar condition prevailed in case of small macro-aggregates for plant mixture where no effect of drought was found in small macro-aggregates. However, for plant mixture, significant increase in micro-aggregate fraction corresponding to a significant decrease in macro-aggregate fraction was found. This was attributed to reduced supply of root exudates to soil that disturbed the stability of macroaggregates (Jastrow 1998). Lack of binding agent under moisture stressed condition disintegrates soil aggregates into fine sized micro-aggregates (Jastrow 1998). Thus, it is apparent that fluctuations in soil moisture regime can substantially alter the arrangement of soil particles.

\section{Nitrogen incorporation in soil aggregates}

Nitrogen incorporation in bulk soil was not affected by drought stress (Fig. 2). Drought had no significant effect on $\mathrm{N}$ allocation in the finer aggregates except for soils under plant mixture (Fig. 2d) where the allocation increased significantly from $0.128 \pm 0.004 \%$ to $0.146 \pm 0.006 \%$.

Total soil $\mathrm{N}$ is involved in the formation of aggregates that is why it has been regarded as an indicator of soil aggregate stability (Chaney et al. 1984). In this study, total $\mathrm{N}$ content was found to be allocated more in macro-aggregate fraction compared to micro-aggregates due to the presence of more mineralizable $\mathrm{N}$ as a percent of the total organic $\mathrm{N}$ in the bigger aggregates (Elliott 1986). This condition has also been referred to the resistant nature of soil under drought stress (Six et al. 1998). This also explains that the $\mathrm{N}$ associated with this fraction is better protected against microbial/enzymatic degradation and is thus less decomposed than the other fractions (Puget et al. 2000). Soil N was almost unaffected throughout the study period which can be related to a very slow turnover rate of soils (Tiessen, Stewart 1983). The more stable nature of macro-aggregates was attributed to the

$$
-|6|-
$$


reluctance of bigger aggregates to change their nutrient composition (Elliott 1986). The unaltered $\mathrm{N}$ content in the micro-aggregate fraction was associated with the limit of $\mathrm{N}$ that can be held in this fraction, after which further allocation is restricted (Hassink 1997).

(a) Unplanted
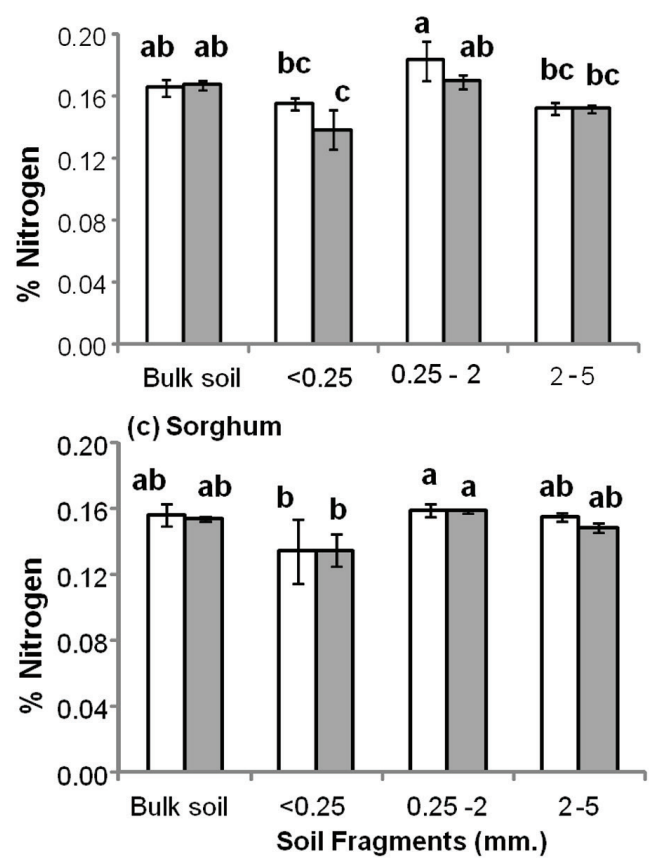

(b) Maize

$\square$ Optimum

$\square$ Drought
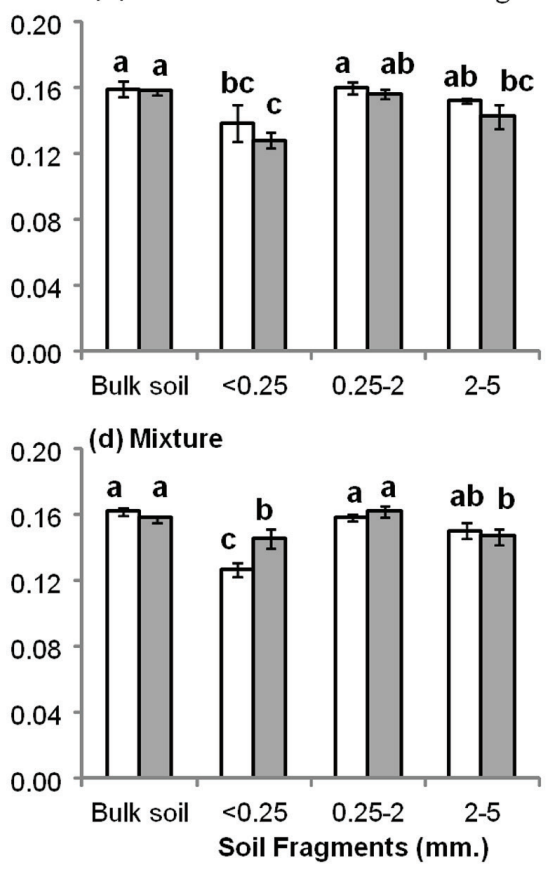

Fig. 2: Effect of drought in total N-content (\%) in different soil aggregates under (a) unplanted condition, (b) maize monoculture, (c) sorghum monoculture and (d) maize-sorghum intercropping. All value represent mean $\pm \mathrm{SD}(\mathrm{n}=3)$.

Further, drought caused a significant increase in the total $\mathrm{N}$ content for plant mixture under moisture stress. Fine soil particles in micro-aggregate fraction contain several types of binding agents whose effects are additive that increase micro-aggregate proportion in the aggregate fractions (Oades, Ladd 1977) as was observed for plant mixture in this study.

\section{Incorporation of ${ }^{15} \mathbf{N}$ in soil aggregates}

Drought didn't affect the $\%$ of ${ }^{15} \mathrm{~N}$ recovered either in bulk soil or in different soil aggregate fractions in either of the plant monocultures. For unplanted control soils 
too, no effect was observed except for small macro-aggregate fraction. For plant mixture, recovery of ${ }^{15} \mathrm{~N}$ increased significantly in bulk soil from $12.26 \pm 1.22 \%$ to $21.48 \pm 7.71 \%$ (Fig 3). The proportion of ${ }^{15} \mathrm{~N}$ recovered was uniform in bulk soil for unplanted control soils and for soils planted under plant monocultures which reflects the lower capacity of nitrogen uptake and supply (Kong et al. 2007). This steady state has been attributed to immobilization process that obstructed the decomposition of $\mathrm{N}$ at the soil surface (Séquaris et al. 2010). Earlier studies have demonstrated that crops take up a greater proportion of recently added nitrogen rather than those derived from cover crops (Ladd, Amato 1986).

(a) Unplanted control

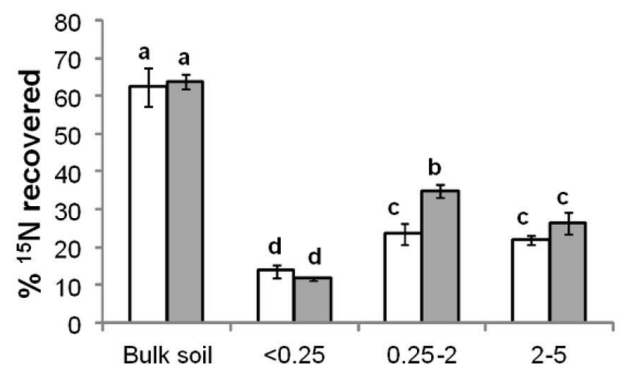

(c) Sorghum

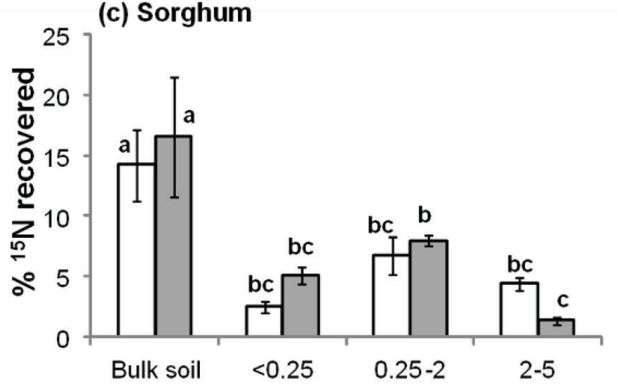

(b) Maize

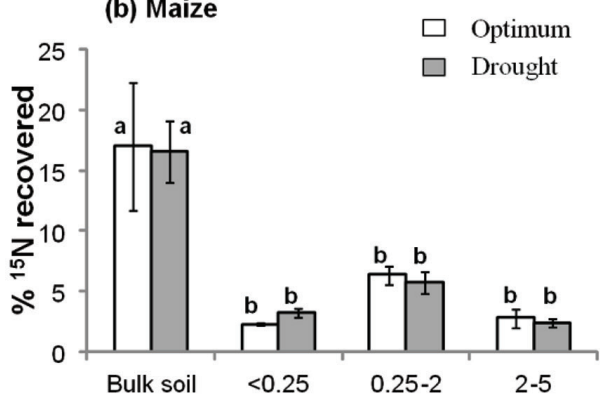

(d) Mixture

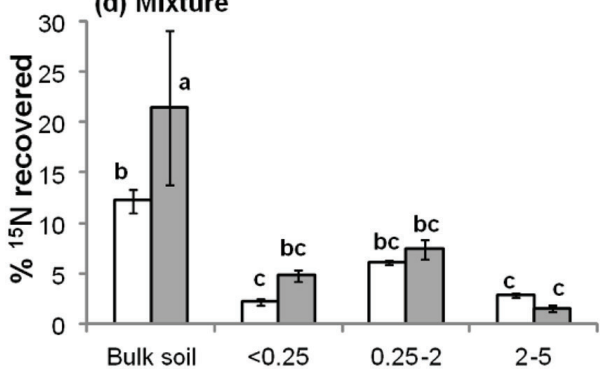

Fig. 3: Drought effect in ${ }^{15} \mathrm{~N}$ content under different soil aggregates in (a) unplanted condition, (b) maize monoculture, (c) sorghum monoculture and (d) intercrop of maize-sorghum. All values represent mean $\pm \mathrm{SD}(n=3)$.

Further, nutrient decomposition in finer aggregates containing the recently added nutrients is found to be very slow compared to the bigger fractions which negate the possibility of nutrient release from micro-aggregate fractions to bigger aggregate fractions (Jenkinson 1977). Similarly, drought did not affect ${ }^{15} \mathrm{~N}$ recovery in bigger aggregates for planted soils which can be attributed to lack of soil disturbance as soil aggregates are normally found to disintegrate and release nutrients into other 
soil fractions when disturbed (Puget et al. 2000). The nutrient allocation in bigger soil aggregates is favored by avoiding soil disturbance (Cambardella, Elliott 1993) which might have resulted in the increased recovery of ${ }^{15} \mathrm{~N}$ in small macroaggregate fraction for unplanted control soils. The tendency of releasing recent nitrogenous compounds from soil organic pool into bulk soil (Jordan et al. 1993) may have increased ${ }^{15} \mathrm{~N}$ recovery in bulk soil for plant mixture. This increase has also been correlated to death of microbes caused by drought stress that resulted in the leaching of ${ }^{15} \mathrm{~N}$ into the soil (Miller et al. 2005). Thus, drought didn't affect the recovery of ${ }^{15} \mathrm{~N}$ in plant monocultures but intercropping substantially increased recovery of ${ }^{15} \mathrm{~N}$ in bulk soil.

\section{Conclusion}

Moisture stress affected the distribution of soil aggregates and $\mathrm{N}$ uptake in different soil aggregate fractions. Soil aggregates were predominantly distributed in small macro-aggregates irrespective of moisture stress. Soils under sorghum monoculture were the most affected as they disintegrated into finer aggregates; however, these changes didn't alter $\mathrm{N}$ uptake. For maize monoculture, there was a decrease in the proportion of aggregates in small macro-aggregate fraction but didn't induce any change in $\mathrm{N}$ uptake within the soil aggregates. For plant mixture, soil aggregates dissociated from macro-aggregate to micro-aggregate fractions increasing the total nitrogen content in micro-aggregate fractions.

Hence maize-sorghum intercropping resisted decrease in $\mathrm{N}$ content in soil aggregates and increased the uptake of added $\mathrm{N}$ emphasizing its usefulness in $\mathrm{N}$ conservation during water stress period and reutilizing them in the growth period. This also emphasizes the usefulness of maize and sorghum in agroforestry system. Studies have shown that productivity of maize increases when intergrown with legume trees and also for sorghum when intergrown with Azadirachta indica and Albizzia lebbeck. Thus, intergrowing maize and sorghum with appropriate tree species will produce advantageous effects for both crops. 


\section{Literature Cited}

Amoako-Atta B., Omolo E. O., Kidega E.K. (1983): Influence of maize, cowpea and sorghum intercropping systems on stem-/pod-borer infestations. International Journal of Tropical Insect Science.4:47-57.

Cambardella C., Elliott E. (1993): Carbon and nitrogen distribution in aggregates from cultivated and native grassland soils. Soil Science Society of America Journal.57:1071-1076.

Carlsson-Kanyama A. (1998): Climate change and dietary choices - how can emissions of greenhouse gases from food consumption be reduced? Food Policy.23:277-293.

Chaney K., Swift R. S. (1984): The influence of organic matter on aggregate stability in some British soils. The Journal of soil science.35:223-230.

Elliott E. T. (1986): Aggregate Structure and Carbon, Nitrogen, and Phosphorus in Native and Cultivated Soils. Soil Sci. Soc. Am. J.50:627-633.

Farooq M., Wahid A., Kobayashi N., Fujita D., Basra S. (2009): Plant drought stress: effects, mechanisms and management. In Sustainable Agriculture (Springer): 153-188.

Hansen J., Ruedy R., Sato M., Lo K. (2006): GIS Surface Temperature Analysis. Global Temperature Trends: 2005 Summation.

Hassink J. (1997): The capacity of soils to preserve organic C and N by their association with clay and silt particles. Plant and soil.191:77-87.

Jacoby G. C., D’Arrigo R. D., Davaajamts T. (1996): Mongolian tree rings and 20th-century warming. Science. 273:771-773.

Jastrow J. D. (1998): Contributions of interacting biological mechanisms to soil aggregate stabilization in restored prairie. Soil biology \& biochemistry.30:905.

Jenkinson D. S. (1977): Studies on the decomposition of plant material in soil. $\mathrm{V}$. the effects of plant cover and soil type on the loss of carbon from ${ }^{14} \mathrm{C}$ labeled ryegrass decomposing under field conditions. The Journal of soil science.28:424-434.

Jordan D., Rice C. W, Tiedje J. M. (1993): The effect of suppression treatments on the uptake of ${ }^{15} \mathrm{~N}$ by intercropped corn from labeled alfalfa (Medicago sativa). Biology and fertility of soils. 16:221-226.

Kong A. Y., Fonte S. J., Kessel C. v., Six J. (2007): Soil aggregates control N cycling efficiency in long-term conventional and alternative cropping systems. Nutrient Cycling in Agroecosystems.79:45-58. 
Kuzyakov Y., Xingliang X. (2013): Competition between roots and microorganisms for nitrogen: mechanisms and ecological relevance. New phytologist.198:656-669.

Ladd J., Amato M. (1986): The fate of nitrogen from legume and fertilizer sources in soils successively cropped with wheat under field conditions. Soil Biology and Biochemistry. 18:417-425.

McCright A. M., Dunlap R. E. (2000): Challenging global warming as a social problem: An analysis of the conservative movement's counter-claims. Social Problems. 499-522.

Miller A. E., Schimel J. P., Meixner T., Sickman J. O., Melack J. M. (2005): Episodic rewetting enhances carbon and nitrogen release from chaparral soils. Soil Biology and Biochemistry. 37:2195-2204.

Muchow R. (1989): Comparative productivity of maize, sorghum and pearl millet in a semi-arid tropical environment II. Effect of water deficits. Field Crops Research.20:207-219.

Oades J. M., Ladd. J. N. (1977): Biochemical properties: carbon and nitrogen metabolism. Soil Factors in Crop Production in a Semi-arid Environment: 127-162.

Olesen J. E., Bindi M. (2002): Consequences of climate change for European agricultural productivity, land use and policy. European journal of agronomy.16:239-262.

Puget P., Chenu C., Balesdent J. (1995): Total and young organic matter distributions in aggregates of silty cultivated soils. European Journal of Soil Science.46:449-459.

Puget P., Chenu C., Balesdent J. (2000): Dynamics of soil organic matter associated with particle-size fractions of water-stable aggregates. European Journal of Soil Science.51:595-605.

Rillig M. C., Field C. B., Allen M. F. (1999): Fungal root colonization responses in natural grasslands after long-term exposure to elevated atmospheric $\mathrm{CO}_{2}$. Global Change Biology. 5:577-585.

Séquaris J. M., Herbst M., Weihermüller L., Bauer J., Vereecken H. (2010): Simulating decomposition of ${ }^{14} \mathrm{C}$-labelled fresh organic matter in bulk soil and soil particle fractions at various temperatures and moisture contents. European journal of soil science. 61:940-949.

Singer M., Southard R., Warrington D., Janitzky P. (1992): Stability of synthetic 
sand-clay aggregates after wetting and drying cycles. Soil Science Society of America Journal. 56:1843-1848.

Six J., Elliott E., Paustian K., Doran J. (1998): Aggregation and soil organic matter accumulation in cultivated and native grassland soils. Soil Science Society of America Journal. 62:1367-1377.

Somma F., Hopmans J., Clausnitzer V. (1998): Transient three-dimensional modeling of soil water and solute transport with simultaneous root growth, root water and nutrient uptake. Plant and Soil.202:281-293.

Tiessen H., Stewart J. W. B. (1983): Particle-size Fractions and their use in studies of soil organic matter: II. Cultivation Effects on Organic Matter Composition in Size Fractions. Soil Sci. Soc. Am. J.47:509-514.

Tilander Y. (1993): Agroforest Syst. 24:277. https://doi.org/10.1007/BF00705627. Willey R., Natarajan M., Reddy M., Rao M., Nambiar P., Kannaiyan J., Bhatnagar V. (1980): Intercropping studies with annual crops. Better Crops for Food". 83-97.

Zhang F., Li L. (2003): Using competitive and facilitative interactions in intercropping systems enhances crop productivity and nutrient-use efficiency. Plant and soil.248:305-312. 